\title{
CANOPY PROFILING FOR VEGETATION MAPPING IN SOUTH-WESTERN AUSTRALIAN FORESTED ECOSYSTEMS
}

\author{
A.G.T. Schut ${ }^{\mathrm{a}, *}$, G. W. Wardell-Johnson ${ }^{\mathrm{a}}$, I. Baran ${ }^{\mathrm{b}}$ \\ ${ }^{a}$ Curtin Institute for Biodiversity and Climate, Curtin University, Kent St Bentley, WA - (t.schut, g.wardell-johnson)@curtin.edu.au \\ ${ }^{\mathrm{b}}$ AAM Pty Limited, 1002 Hay St, Perth, WA - i.baran@aamgroup.com
}

Commission VII, WG VII/7

KEY WORDS: LIDAR, Vegetation, Geomorphology, Object, Classification, Recognition

\begin{abstract}
:
Anthropogenic climate change is already impacting native vegetation world-wide. Thus accurate mapping of current vegetation condition is necessary for benchmarking and conservation planning. We examine the potential for the mapping of native vegetation of forested ecosystems in south-western Australia using LiDAR data. Airborne LiDAR (distance between data points $1.2 \mathrm{~m}$ ) and RGB imagery was acquired with a discrete 4-return Leica ALS 50-II system in April 2011 and vertical canopy profiles determined in Boyagin Nature Reserve. Elevation, slope and geomorphological descriptions of the terrain in combination with vertical canopy profiles based on presence/absence of returns within voxels were derived from the LiDAR data and processed at a spatial resolution of 4.0 meters. Based on these profiles, crown height and depth, ground cover, mean intensity of crown returns, presence of understory and number of vegetation layers were determined for each grid cell. Unsupervised classification revealed distinctive canopy profiles. Vegetation is strongly linked to geomorphology in this old landscape. Thus Kwongan shrubland occurs on the plateaus, Allocasuarina heugeliana woodland on the fringes of rock outcrops, Eucalyptus astringens and E. accedens woodland on breakaways and E. wandoo and Corymbia calophylla woodland in more fertile valley systems. The vegetation types present within distinctive spatial clusters were determined in two field visits. Vegetation types were mapped with an object-based image analysis approach at geomorphological, vegetation and tree scales using the geomorphology of the terrain and structural, textural and reflective characteristics of the canopy. All vertical profiles identified were present on each geomorphological unit. Tree species with a distinctive vertical profile such as Eucalyptus astringens and Allocasuarina heugeliana were defined and distinguished in combination with object-based geomorphological and spatial characteristics. Vegetation types were mapped accurately with a kappa coefficient of 0.80 . We conclude that vertical profiles and geomorphology of the terrain derived from commercially available discrete return LiDAR systems provides a valuable means to benchmark the mapping of native vegetation in the forested ecosystems of south-western Australia.
\end{abstract}

\section{INTRODUCTION}

Regional mapping of vegetation is important for conservation planning and natural resource management (Wardell-Johnson and Williams 1996; Lawson and Wardell-Johnson 2006). South-western Australian forested ecosystems are under serious pressure from anthropogenic climate change (Medlyn et al. 2011). Accurately mapping the vegetation structure and biodiversity patterns in this global biodiversity hotspot is therefore vitally important for benchmarking and conservation planning in the face of anthropogenic climate change. However, vegetation mapping (type, condition, structure or floristic patterns) can be problematic in old and stable, but heterogeneous landscapes (Wardell-Johnson and Williams 1996; Mucina and Wardell-Johnson 2011), exemplified by much of south-western Australia. In this region, landscapes are muted and vegetation overstorey canopy relatively constant, despite a highly heterogeneous understorey associated with the geomorphology of these landscapes (Wardell-Johnson and Williams 1996). Complexity in vegetation mapping is amplified by disturbance, with temporal heterogeneity exacerbated in areas that include recent disturbance (e.g. fire).

At the regional scale, identification of map units is mostly based on overstorey following the interpretation of aerial photography and remote sensing imagery, using associations with environmental variables (Nelder, 2003). Ideally, mapped polygons represent distinct boundaries in vegetation types, and consist of homogeneous units (see Lawson and WardellJohnson 2006). Vegetation types with similar spectral and textural characteristics cannot be identified from photointerpretation easily, leading to a poor representation of floristic patterns within such heterogeneous ecosystems (WardellJohnson et al. 2006). There are strong associations between geomorphological units and vegetation (Beard 1990) in the old landscapes of south-western Australia, despite consistency in overstorey structure. Furthermore, the geomorphology is complex with intertwined mosaics and subtle changes, resulting in distinct vegetation types occurring within short distances. Consequently vegetation maps represent combined vegetation types, obscuring variation in floristic patterns (Wardell-Johnson and Williams 1996). The advances of full waveform and discrete return LiDAR technology provides a new range of tools for characterisation of vegetation (Wulder et al. 2008; Mallet and Bretar 2009), including measurement of key vegetation type attributes height and crown density (Sun et al. 1997).

Characterization of specific vegetation components with LiDAR is promising for the identification of tree types, coverage and height (St.-Onge et al. 2003; Korpela et al. 2010), quantification of stem location, diameter and carbon content (Means et al. 1999; Bork and Su 2007; Lee and Lucas 2007). Dense point clouds also provide a means to use 3D modelling approaches for tree crown identification and measurement (Reitberger et al. 2009). Alternatively, distribution models fitted to vertical profiles have been used to characterise a limited number of tree 
species (Jaskierniak et al. 2011), although these methods are computationally intensive. However, most of these methods are only available for dense point clouds, with typically 4-6 returns $/ \mathrm{m}^{2}$.

The aim of this work is to develop a methodology that defines map units based on geomorphological features of the landscape with a homogeneous vegetation structure to identify floristically relevant map units in comparable condition. To this end, distinct vertical canopy profiles were generated from moderate point density LiDAR data and used to map the native vegetation of Boyagin Nature Reserve, south-western Australia.

\section{MATERIALS AND METHODS}

\subsection{Boyagin Nature Reserve}

Boyagin Nature Reserve (Boyagin) is $49 \mathrm{~km}^{2}$ in area and is located on the eastern edge of the Jarrah Forest Bioregion in south-western Australia (McKenzie et al. 1996). The study included only the western part of the reserve, an area of 27.5 $\mathrm{km}^{2}$. The area is dominated by Kwongan scrublands and Eucalyptus woodlands (Dames and Moore 1985). Boyagin has extensive areas with characteristic Kwongan (shrub/heath) communities dominated by Banksia nobilis, Eucalyptus drummondii and E. caesia and by Banksia attenuata and B. grandis (Dames and Moore 1985). 14 associations of woody plant communities were identified by Dames and Moore in their vegetation map of the area (Dames and Moore 1985). The woodland areas include the overstorey species Allocasuarina campestris and A. huegeliana, Eucalyptus wandoo, E. accedens, E. loxophleba, E. astringens and E. marginata as well as Corymbia calophylla, Acacia acuminata, and A. lasiocalyx. Diverse herbfields occur on shallow soils near granite outcrops (Dames and Moore 1985). Due to “... considerable variation in height, density and species proportions in tree overstorey as well as in their shrub understoreys" vegetation maps drawn by different people result in maps "for the same area that have different boundaries and designations" (Dames and Moore 1985, page 11).

This area is a complex dissected old lateritic plateau with granite outcropping on dissected slopes. Gravelly soils occur on the plateau with pockets of light coloured deep or loamy sand. These are highly reflective soils occurring in a complex mosaic of remnant drainage systems. There is a close relationship between vegetation type and the presence of laterites and soil fertility in these old, weathered landscapes (Hopper 1979; Beard 1990), which is driven mainly by the ability to compete for available nutrients and to cope with fire (Mucina and WardellJohnson 2011). The laterites may be residual, colluvial near breakaways, or podzolic and formed in-situ in the presence of cluster-root bearing taxa (e.g. Proteaceae) (Verboom and Pate 2003). At the breakaways, loamy or sandy soils occur over gravel, and at the lower foot-slopes mottled clays and sands or sandy loam overlaying clay. Soil fertility is generally low, but availability of nutrients is higher in areas of fresh weathering granitic rocks and nearby alluvial fans (Verboom and Pate 2003). Verboom and Pate (2003) argue that grey sands in this landscape are residual or alluvial, whereas yellow sands may have formed as a result of weathering lateritic material linked to the presence of cluster-root bearing taxa. In Boyagin, these grey/white sands are linked to the sclerophyllous shrublands with Xanthorrhoea preissii, while pockets with yellow sand may be linked to diverse Kwongan communities with a high proportion of Proteaceae, Myrtaceae and Leguminosae species (Dames and Moore 1985).

South-western Australia is experiencing a strong drying and warming trend (Bates et al. 2008). This is reflected in recent weather patterns in the time leading up to LiDAR coverage. The rainfall in 2010 started particularly late, and was already over in late September, resulting in an extreme low rainfall year. This was followed by a long dry summer leading up to the acquisition of airborne data. Thus, this dry period is reflected in the vegetation, which features low coverage and many dead shrubs and trees.

\subsection{Available remote sensing data}

In April 2011, airborne LiDAR data and RGB imagery were acquired by AAM for the western part of the Boyagin Nature Reserve as part of a campaign covering 29 Granite outcrop areas scattered throughout south-western Australia. In 2011, the aircraft flew about $1700 \mathrm{~m}$ above ground and scanned approximately $1.5 \mathrm{~km}$ wide swaths, resulting in a distance between points on the ground of about $1.2 \mathrm{~m}$ and 0.63 points $\mathrm{m}^{2}$, with a relative horizontal and vertical accuracy of $<0.24 \mathrm{~m}$ and $0.15 \mathrm{~m}$ respectively. The Leica ALS 50-II scanner recorded 4 discrete returns, with a footprint of about $0.39 \mathrm{~m}^{2}$.

A Landsat Thematic Mapper image (8 April 2011) was acquired and atmospherically corrected using the Chavez' COST approach (Chavez 1996). The tasselled cap transformed (TCT) images were determined and the brightness image was used to identify areas with highly reflective soils.

\subsection{LiDAR data processing}

After initial classification into ground and non-ground, misclassifications were found for overlapping runs. A DEM of the terrain was derived from triangulation of all ground points which was consequently used to determine the height above ground for all returns classified as non-ground (see Jaskierniak (2011) for a detailed description of the procedure).

Overlapping areas of adjacent runs produced strips with a denser point cloud. These variations in point density are undesired (Jaskierniak et al. 2011). Initially, all layers were processed in a 4 by $4 \mathrm{~m}$ raster. For each cell with overlapping runs, only points were included from the run with smallest mean scan angle. This produced grid cells with up to 32 returns per cell, although 11-15 returns were typically found in vegetated areas with trees. However, subtle variations in point density occur throughout the flight, potentially resulting in distinct percentages of returns per defined vertical layer. Therefore, presence and absence of vegetation was recorded in voxels, as presence / absence recordings of vegetation in voxels are less sensitive to these point cloud density variations.

For each vertical layer of $1 \mathrm{~m}$ height, percentages of filled voxels (PFV) were computed within a $3 \times 3$ window, producing a vertical PFT profile for each grid cell. These PFV profiles were smoothed to better define the top and bottom of canopy layers. Smoothing was applied in the vertical direction by applying a simple filter (Gaussian $3 \times 1$ filter with weights of $0.27,0.46$ and 0.27 ) and sampled at $1 \mathrm{~m}$ height intervals to $6 \mathrm{~m}$, thereafter $2 \mathrm{~m}$ intervals to $20 \mathrm{~m}$ and 20 and 30 meters height, and saved as GEOTIFF images for further processing.

Following the approach of Reitberger (2009), thresholds of 20 and $40 \%$ (i.e. 4 out of 9 voxels) were initially used to trigger 
the start and the end of a vegetation layer within a PFV profile. For the first two layers, the height of the top, the thickness of the crown, mean coverage and mean intensity were determined. Return number has a profound influence on the recorded intensity (Morsdorf et al. 2010). Therefore, only first and single returns were used to determine the mean intensity.

Laser data were further classified according to the type and elevation of the returns (Miura and Jones 2010), where 4 vegetation layers were identified: low vegetation $(<1 \mathrm{~m}$ above the ground), medium vegetation (1-3 m), high vegetation (3-10 $\mathrm{m})$ and top vegetation $(>10 \mathrm{~m})$. For each layer, an open, dense and total fraction was determined. Open refers to first or single return points without vegetation above, dense to intermediate or last returns (Miura and Jones 2010).

Percentages of cover in voxel layers at above mentioned sampled heights and height of the top, cover, intensity and crown height of the top canopy layer were transformed into principle components. The significant bands, capturing $99 \%$ of the variation, were clustered using the iterative, self-organising (ISO) clustering technique, constrained to contain at least $2 \%$ of pixels.

\subsection{Geomorphological units}

Following the approach used by Bork and Su (2007), geomorphological classes based on slopes were derived from the DEM. In this undulating area, differentiation into low and high areas failed to identify important breakaway areas. Therefore, short distance slope classes $(<6,<9,<20,<40$ and $>=40 \%$ ) and medium distance slope classes ( $<10 \%$ flat, $<20 \%$ breakaways, $>=20 \%$ outcrops) were defined, based on the maximum slope in a $4 \mathrm{~m}$ and $120 \mathrm{~m}$ radius respectively. Areas with a medium distance slope below $10 \%$ were further subdivided into high and low elevation areas, resulting in a total of 20 geomorphological classes.

\subsection{Ground data collection}

Areas with distinct profiles near tracks were visited. The vegetation present was described (in broad terms) and georeferenced photographs taken at each site. A total of 138 random validation points were generated within $50 \mathrm{~m}$ of the geo-referenced sites to ensure that the points were well away from transition zones near the track. The vegetation description in combination with interpretation of RGB airborne imagery was used to ensure that the correct vegetation type was assigned. From these validation points, overall accuracy and the kappa coefficient were calculated for accuracy assessment.

\subsection{Objects for further processing}

The generated layer characteristics, PFV profiles, DEM and Landsat imagery were included in an object-based image classification (eCognition). This was used to generate three object levels: a broader scale level based on geomorphological units, a vegetation level based on iterative, self-organising (ISO) data classification, intensity, tasselled cap transformed (TCT) brightness and greenness to identify units with homogeneous vertical profiles and soil backgrounds, and a tree level to delineate and classify individual trees based on canopy layer characteristics.

The tree level was first classified based on the most frequently occurring ISO profile. These ISO-classes in the tree level were used to classify objects at the vegetation level into three classes: woodlands; small trees or mallee; and shrublands. For this, logistic type membership functions were based on the occurrence of the ISO classes. With similar coverage of ISOclasses, an object was more likely to be assigned to trees than to shrubland. Firstly, shrublands were further classified according to most occurring ISO-classes, see Table 1 . Secondly, small trees or mallee shrubs were further classified with a nearest neighbour classifier trained on the coverage of ISO-classes, TCT greenness, relief and means of top canopy layer characteristics (height of vegetation, crown thickness, coverage and intensity). This classifier was then used to classify $E$. accedens and Acacia trees, mallee vegetation dominated by Acacia lasiocalyx or Allocasuarina campestris, and shrubland with E. drummondi or E. exilis emergent.

At the tree level, high trees were classified according to ISOclasses and relief classes (Table 1). The ISO classes were not specific to a single species. Therefore, $E$. wandoo trees were more likely to occur in flat areas below breakaways and lowland areas, E. marginata in areas classified as E. exilis or kwongan shrubland (Kwongan areas) and E. astringens to steep sloping areas below breakaways. Additional conditions were set to differentiate E. calophylla (TCT greenness) from E. astringens (crown height and number of canopy layers) and E. wandoo.

Each object level was exported as a shapefile, where the vegetation objects were intersected with a vegetation type layer, as determined from the ground truth to identify objects for validation purposes.

\begin{tabular}{llcccccc}
\hline & PFV profile & Ht1 & Cn1 & Cv1 & Int1 & Ht2 \\
\hline 1 & - & - & - & - & - & - \\
\hline $\begin{array}{l}\text { No vegetation } \\
\text { Shrubs. Some shrubs near } \\
\text { tree }\end{array}$ & 0.5 & 1.5 & 0.7 & 11.2 & 10.8 & - \\
$\begin{array}{l}\text { Shrubs. Very patchy } \\
\text { shrubs near a tree }\end{array}$ & 1.1 & 7.9 & 3.2 & 22.0 & 18.2 & 0.8 \\
3 & $\begin{array}{l}\text { Shrubs. Low coverage } \\
\text { Shrubs. Some shrub near } \\
\text { high tree }\end{array}$ & 0.2 & 1.7 & 0.4 & 5.4 & 5.2 & - \\
6 & $\begin{array}{l}\text { Small trees or mallee. } \\
\begin{array}{l}\text { Patchy. } \\
7\end{array}\end{array}$ & 1.1 & 5.8 & 3.7 & 30.2 & 20.1 & 0.5 \\
$\begin{array}{l}\text { Small trees or mallee. } \\
\text { Open } 8 \text { m crown, } \\
\text { understory }\end{array}$ & 1.1 & 9.0 & 7.2 & 36.6 & 14.1 & 0.2 \\
8 & $\begin{array}{l}\text { Small trees or mallee. } \\
\text { Patchy, open with } \\
\text { understory }\end{array}$ & 1.3 & 10.5 & 6.0 & 28.2 & 13.2 & 1.4 \\
9 & $\begin{array}{l}\text { High trees. Dense patchy } \\
\text { vegetation }\end{array}$ & 1.1 & 9.4 & 4.6 & 29.8 & 19.3 & 0.3 \\
10 & $\begin{array}{l}\text { High trees. Thick dense } \\
\text { crown }>10 \text { m }\end{array}$ & 1.1 & 10.8 & 8.0 & 37.5 & 13.5 & 0.3 \\
11 & $\begin{array}{l}\text { High trees }>10 \text { m, minor } \\
\text { understory }\end{array}$ & 1.1 & 12.1 & 5.1 & 29.4 & 17.6 & 0.6 \\
12 & $\begin{array}{l}\text { High trees }>15 \text { m , leafy } \\
\text { crown }\end{array}$ & 1.3 & 16.4 & 6.4 & 30.4 & 19.7 & 2.1 \\
13 & $\begin{array}{l}\text { High trees, thick dense } \\
\text { crown }>10 \text { m }\end{array}$ & 1.2 & 12.4 & 7.8 & 36.5 & 14.5 & 0.6 \\
14 & $\begin{array}{l}\text { High trees 15 m , thin } \\
\text { crown with high dense } \\
\text { understory }\end{array}$ & 1.3 & 14.9 & 9.2 & 34.9 & 15.8 & 1.0 \\
\hline
\end{tabular}

Table 1. Means of the top two canopy layer characteristics: number of canopy layers (Nl), height of dense top (Ht1) and second (Ht2) crown above ground, crown thickness (Cn1), ground coverage of crown (Cv1) and first and single return intensity (Int1) for each distinct vertical canopy profile. 


\section{RESULTS}

Six PC images were required to capture 95\%, and 9 PCs for $99 \%$ of the total variation in the layers as derived from the LiDAR dataset. This highlights the richness of LiDAR data. The 14 distinctive PFV profiles identified, with at least $2 \%$ coverage, showed clear differences in the number of canopy layers present, but also the intensity of the first or single returns (Table 1). The system used recorded intensity in the NIR wavelength, and differences in intensity are therefore related to the presence and orientation of green leaf material.

The distinct PFVs were spatially clustered and linked to relief (Figures 1 and 2). However, these distinct profiles are not unique to vegetation types. Rather, vegetation types show a typical relative coverage of several of these profiles. For example, the areas with Kwongan will have a large coverage with low vegetation and a low coverage with tall trees.

Stands with E. astringens had a typical profile with a high top, a thin crown without understory as "E. astringens usually do not have a clear understory" (Dames and Moore 1985). The abundance of E. astringens stands is low, so wasn't recognized as a separate ISO-profile - rather occurring with other tree species in one ISO class. However, this vegetation type could be identified when including height of the crown base, the relative cover of shrubs and the relief class associated with steep slopes near breakaways.

Stands with A. heugeliana were characterized by the presence of dense cover and of a distinct vertical profile (for $10 \mathrm{~m}$ high trees). Tall trees of $E$. wandoo and $E$. accedens were difficult to separate based on the PFV profile alone. Based on general

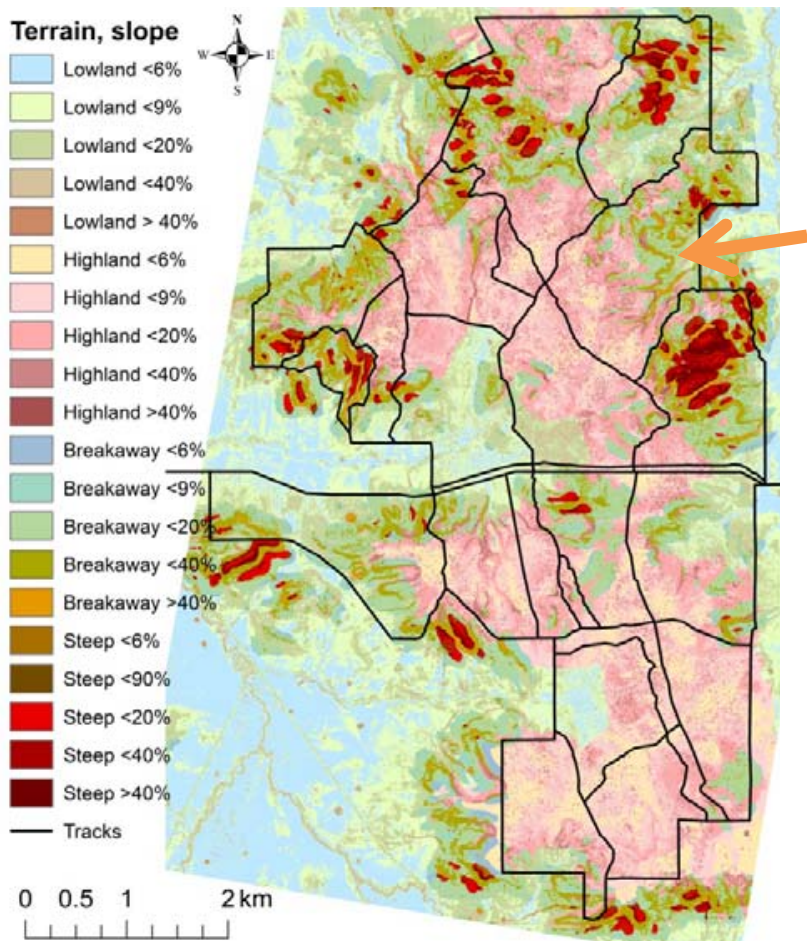

Figure 1. Geomorphological classes for the area scanned with LiDAR and tracks within the western part of Boyagin Nature Reserve. The orange arrow indicates the direction of view in Figure 2.

\begin{tabular}{|c|c|c|c|}
\hline Vegetation & $\begin{array}{l}\text { Dominant } \\
\text { overstorey } \\
\text { species }\end{array}$ & $\begin{array}{c}\text { Trees } \\
\text { (ha) }\end{array}$ & $\begin{array}{l}\text { Vegetation } \\
\text { (ha) }\end{array}$ \\
\hline \multirow{6}{*}{ Woodlands } & A. huegeliana & 636.5 & 542.1 \\
\hline & E. accedens & 770.4 & 1014.7 \\
\hline & E. astringens & 9.8 & 15.5 \\
\hline & C. calophylla & 86.8 & 30.4 \\
\hline & E. marginata & 65.4 & 0.0 \\
\hline & E. wandoo & 115.1 & 168.7 \\
\hline \multirow{6}{*}{$\begin{array}{l}\text { Mallee, } \\
\text { small trees }\end{array}$} & Acacia & 39.8 & 78.6 \\
\hline & A. lasiocalyx & 15.4 & 9.1 \\
\hline & A. campestris & 21.5 & 5.7 \\
\hline & E. accedens & 79.3 & 259.3 \\
\hline & E. exilis & 32.0 & 103.5 \\
\hline & E. drummondii & 12.6 & 55.6 \\
\hline \multirow[t]{3}{*}{ Shrublands } & $\begin{array}{l}\text { E. marginata } \\
\text { kwongan }\end{array}$ & 316.2 & 166.2 \\
\hline & $\begin{array}{l}\text { E. accedens } \\
\text { kwongan }\end{array}$ & 377.2 & 211.4 \\
\hline & Low kwongan & 111.0 & 34.8 \\
\hline Uncovered & Granitic or bare & 70.1 & 63.3 \\
\hline
\end{tabular}

Table 2. Area covered per class within the western part of the Boyagin Nature Reserve for defined classes of tree and vegetation objects.

guidelines (Dames and Moore 1985), E. accedens was given a larger likelihood on the highland and breakaway areas and $E$. wandoo on the lowland areas for PFV profile 11. Isolated trees in Kwongan are most commonly E. marginata but individual trees of C. calophylla and E. accedens also occur. These could not be separated within PFV profile 14 and all were assigned to E. marginata.

The largest areas in the reserve are covered by open woodlands with A. huegeliana or E. accedens trees and Kwongan (Table 2 ). When $E$. accedens is present on steep slopes near breakaway zones, it is more commonly present as a small tree, whereas on the highlands it usually occurs as a larger tree. Although many E. marginata trees are present in the reserve, in this area this species is more typically associated with kwongan and therefore, doesn't occur as the dominant tree species in woodlands.

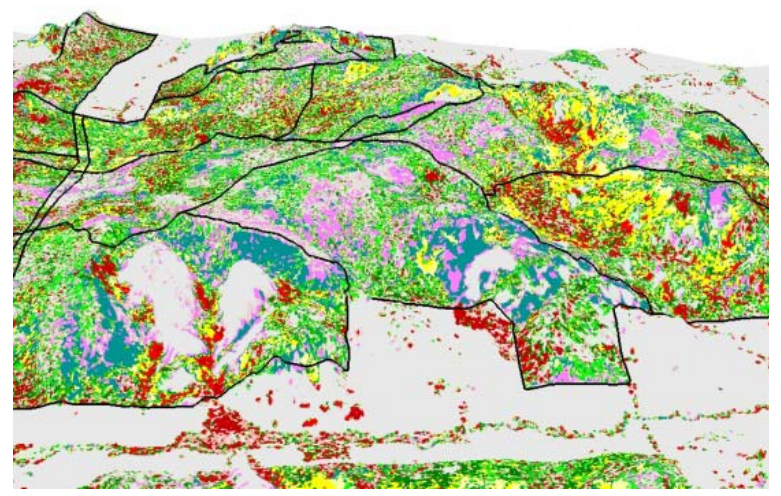

Figure 2. Birds-eye view (elevation exaggerated by a factor 5) highlighting vegetated areas with distinct vertical profiles throughout the western part of Boyagin Nature Reserve (the orange arrow on the left indicates the direction of view). It shows the complex nature of the terrain, and strong associations between canopy structure and position in the landscape. See Table 1 for the legend and description of the classes. 
In general, classified vegetation types match well with observed vegetation for most ground-data points (Figure 3). Ground data points included many observations near transitions of vegetation classes. In general, these boundaries were recognized correctly, although the location of ground points was sometimes problematic. For vegetation objects the dominant species can be arbitrary, and accuracy is finer at the tree level (review the dots in figure 3).

The overall accuracy for the classification of vegetation types was $82 \%$ with a kappa coefficient of 0.80 . Most reference sites were selected near zones of transition between vegetation types. In general, these transitions were reflected accurately in the map although the location of the boundaries between dominating vegetation types caused some misclassifications.

\section{DISCUSSION AND CONCLUSION}

The western part of Boyagin is diverse with a strong mosaic pattern of terrain, soil and vegetation types without strong differences in leaf colour. This limits the accuracy of mapping based on multispectral imagery and / or airborne photography.

Generally, it is recommended to acquire LiDAR with point densities of 4-6 returns $/ \mathrm{m}^{2}$ for characterisation of tree species (Wulder et al. 2008). The method presented in this paper, based on profiles generated from voxel fractions of vegetation presence, provided a cost-effective alternative that successfully characterised the location of trees and could be used to separate current vegetation types with a distinct vertical profile. The voxels were particularly useful to eliminate small spatial variations of point density. The point density of the LiDAR dataset available ( 0.63 points / $\mathrm{m} 2)$ has impacts on details of vegetation that can be recognized, limiting further refinement of classifications into various shrub species. The choice of $4 \mathrm{~m}$ spatial resolution was arbitrary but was considered sufficient as all cells had at least a few LiDAR returns. It is recommended to adjust the voxel sizes according to point densities in the dataset.

Sun et al. (1997) found that Australian land Management Agencies use a range of vegetation type classification schemes but concluded that "most vegetation classification systems used in Australia are similar in using both floristics and structure as two primary elements in classifying vegetation types, and all use growth form (physiognomy) for distinguishing vegetation units”.

The units in the vegetation map that were identified are more detailed than previously available (Dames and Moore 1985). For each unit, a membership value was be derived indicating the confidence in classification. The classification of the more detailed tree objects provides an opportunity to quantitatively characterise each unit in terms of the composition of dominant species present.

The vegetation map produced, with an overall accuracy of $82 \%$ and a kappa coefficient of 0.80 , does reflect only the current situation of combining vegetation type and actual condition. Clearly, fire (time-since; and intensity) strongly affects vegetation structure and thus also influences mapping units as well as classification results. For example, an area with $A$. huegeliana that had recently been burnt by an intense prescribed fire was classified as Kwongan, due to the mostly dead trees and absence of tree crowns in the area. Presumably, with time this area would again be classified as A. huegeliana.

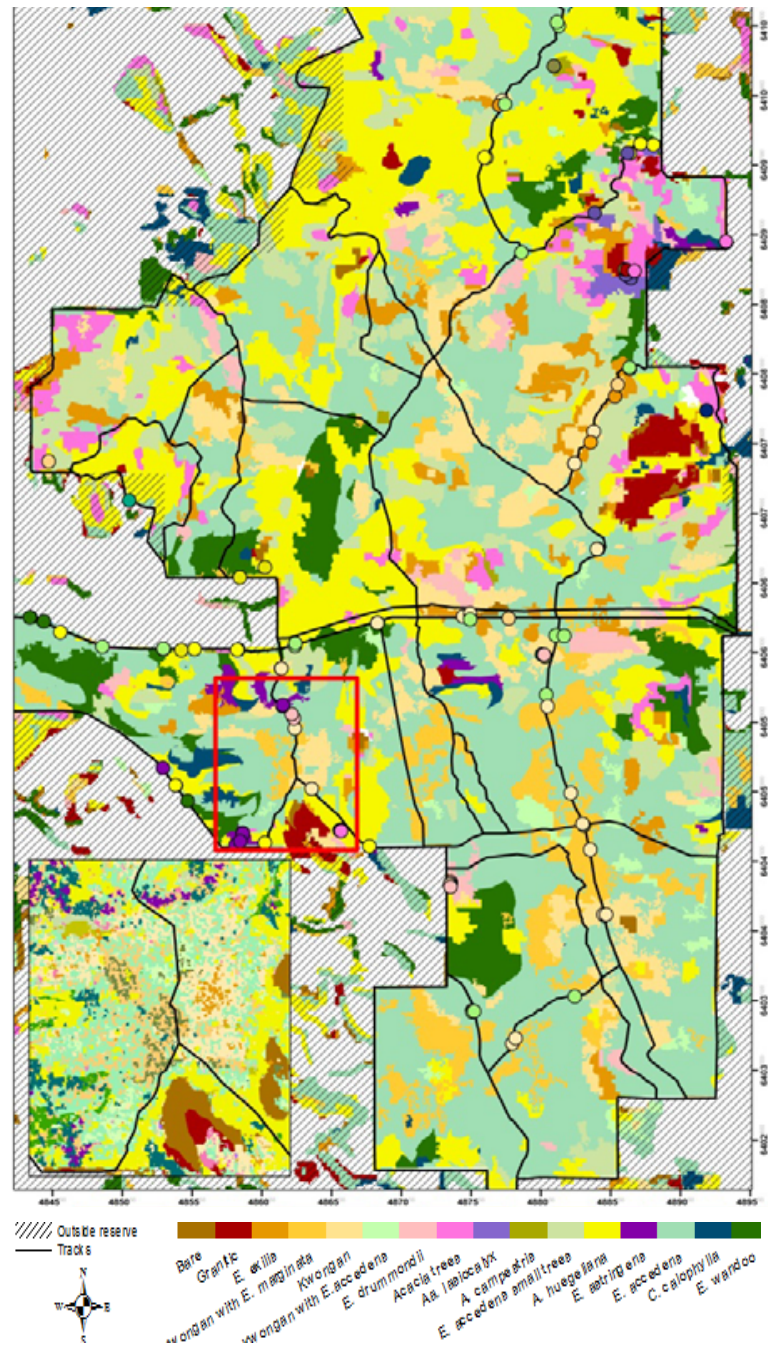

Figure 3. Classifications for vegetation objects in Boyagin Nature Reserve. The circles indicate the approximate location and vegetation type of observations in the field. The inset shows the detailed classification for objects at the tree level.

It is concluded that LiDAR is an extremely useful tool for vegetation type mapping, providing a means to integrate vegetation type, structure of over- and understorey and geomorphology. This is particularly important in old, heterogeneous landscapes. It is expected that species classifications are possible when combined with multispectral datasets from modern high-resolution space-borne sensors. This approach will be crucial for mapping the quantity of carbon that is stored in native vegetation in areas commonly based on species specific allometric relationships.

\section{REFERENCES}

Bates, B. C., P. Hope, B. Ryan, I. Smith and S. Charles, 2008. Key findings from the Indian Ocean Climate Initiative and their impact on policy development in Australia. Climatic Change 89, pp. 339-354. 
Beard, J. S., 1990. Plant life of Western Australia. Kangaroo Press Kenthurst, N.S.W

Bork, E. W. and J. G. Su, 2007. Integrating LIDAR data and multispectral imagery for enhanced classification of rangeland vegetation: A meta analysis. Remote Sensing of Environment 111, pp. 11-24.

Chavez, P. S., 1996. Image-based atmospheric corrections revisited and improved. Photogrammetric Engineering and Remote Sensing 62(9), pp. 1025-1036.

Dames and Moore, 1985. The vegetation of Boyagin Nature Reserve. Perth, Department of Environment and Conservation.

Hopper, S. D., 1979. Biogeographical aspects of speciation in the soutwest Australian flora. Annual Review of Ecology and Systematics 10, pp. 399-422.

Jaskierniak, D., P. N. J. Lane, A. Robinson and A. Lucieer, 2011. Extracting LiDAR indices to characterise multilayered forest structure using mixture distribution functions. Remote Sensing of Environment 115(2), pp. 573-585.

Korpela, I., H. O. Orka, M. Maltamo, T. Tokola and J. Hyyppa, 2010. Tree Species Classification Using Airborne LiDAR - Effects of Stand and Tree Parameters, Downsizing of Training Set, Intensity Normalization, and Sensor Type. Silva Fennica 44(2), pp. 319-339.

Lawson, B. E. and G. W. Wardell-Johnson, 2006. Relating spatial and temporal patterns in floristics with vegetation mapping: an example from Fraser Island, south-east Queensland, Australia. Pacific Conservation Biology 12, pp. 288-300.

Lee, A. C. and R. M. Lucas, 2007. A LiDAR-derived canopy density model for tree stem and crown mapping in Australian forests. Remote Sensing of Environment 111, pp. 493-518.

Mallet, C. and F. Bretar, 2009. Full-waveform topographic lidar: State-of-the-art. ISPRS Journal of Photogrammetry and Remote Sensing 64, pp. 1-16.

Means, J. E., S. A. Acker, D. J. Harding, J. B. Blair, M. A. Lefsky, W. B. Cohen, M. E. Harmon and W. A. McKee, 1999. Use of large-footprint scanning airborne lidar to estimate forest stand characteristics in the Western Cascades of Oregon. Remote Sensing of Environment 67(3), pp. 298-308.

Medlyn, B. E., M. S. J. Zeppel, N. Brouwers, C., K. Howard, E. O’Gara, G. Hardy, T. Lyons, L. Li and B. Evans, 2011. Biophysical impacts of climate change on Australia's forests. Contribution of Work Package 2 to the Forest Vulnerability Assessment. Gold Coast, Australia, National Climate Change Adaptation Research Facility.

Miura, N. and S. D. Jones, 2010. Characterizing forest ecological structure using pulse types and heights of airborne laser scanning. Remote Sensing of Environment 114(5), pp. 1069-1076.

Morsdorf, F., A. Marell, B. Koetz, N. Cassagne, F. Pimont, E. Rigolot and B. Allgower, 2010. Discrimination of vegetation strata in a multi-layered Mediterranean forest ecosystem using height and intensity information derived from airborne laser scanning. Remote Sensing of Environment 114(7), pp. 1403-1415.

Mucina, L. and G. W. Wardell-Johnson, 2011. Landscape age and soil fertility, climatic stability, and fire regime predictability: beyond the OCBIL framework. Plant and Soil 341(1-2), pp. 1-23.

Reitberger, J., C. Schnorr, P. Krzystek and U. Stilla, 2009. 3D segmentation of single trees exploiting full waveform LIDAR data. ISPRS Journal of Photogrammetry and Remote Sensing 64(6), pp. 561-574.

St.-Onge, B., P. Treitz and M. A. Wulder, 2003. Tree and canopy height estimation with scanning LiDAR. In: M. A. Wulder and S. E. Franklin (Eds.). Remote sensing of forest environments : concepts and case studies. Boston, Kluwer Academic Publishers: pp. 489-509.

Sun, D., R. J. Hnatiuk and V. J. Neldner, 1997. Review of vegetation classification and mapping systems undertaken by major forested land management agencies in Australia. Australian Journal of Botany 45(6), pp. 929-948.

Verboom, W. H. and J. S. Pate, 2003. Relationships between cluster root-bearing taxa and laterite across landscapes in southwest Western Australia: an approach using airborne radiometric and digital elevation models. Plant and Soil 248(1-2), pp. 321-333.

Wardell-Johnson, G. and M. Williams, 1996. A floristic survey of the Tingle Mosaic, south-western Asutralia: applications in land use planning and management. Journal of the Royal Society of Western Australia 79, pp. 249-276.

Wardell-Johnson, G. W., B. E. Lawson and R. H. Coutts, 2006. Are regional ecosystems compatible with floristic heterogeneity? A case study from Toohey forest, southeast Queensland, Australia. Pacific Conservation Biology 13, pp. 47-59.

Wulder, M. A., C. W. Bater, N. C. Coops and J. C. White, 2008. The role of LiDAR in sustainable forest management. The Forestry Chronicle 84(6), pp. 1-20.

\section{ACKNOWLEDGEMENTS}

The paper was supported by ARC Linkage Grant LP0990914, a Targeted Fellowship at Curtin University to G.W. Wardell-Johnson and in-kind support from AAM Pty. 